MEXАНIKA

MECHANICS

https://doi.org/10.15407/dopovidi2021.02.021

удК 539.3

Я.Я. Рущицький, член-кореспондент НАН України

Інститут механіки ім. С.П. Тимошенка НАН України, Київ

E-mail: rushch@inmech.kiev.ua

\title{
Аналогії між класичною задачею про коливання двох зв' язаних тіл і некласичною задачею про поширення плоских хвиль у двофазній суміші
}

3 метою виявлення аналогій в процедурах аналізу описано та прокоментовано дві задачі: класичну задачу (задачу К) про гармонічні коливання двох зв'язаних між собою абсолютно твердих тіл, підвішених на пружинах, і некласичну задачу (задачу X) про поширення плоских поздовжніх хвиль у двофазній пружній суміші Побудовано ряд аналогій між цими задачами, які описані у вигляді шести кроків порівняльного аналізу задач $K$ та X, кожен з яких відповідає певній конкретній аналогії. Акцентовано увагу на корисність спостережених аналогій для аналізу задачі про хвилі. Отже, показано, що теорія двофазних сумішей у своєму розвитку в області теорії хвиль може успішно використовувати аналогї з відповідних задач теорї коливань двох взаємозв'язаних коливних систем. 3 наведених аналогій випливає більш загальний факт, що виявлений майже 100 років тому академіком Мандельштамом, механізм взаємодопомоги в теорії коливань за чей час розширив свій вплив і на теорію хвиль.

Ключові слова: коливання двох взаємозв'язаних тіл, поширення пружної плоскої хвилі в двофазній суміші, аналогії в процедурах аналізу.

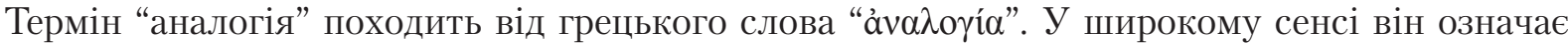
когнітивний процес передачі інформації чи розуміння від одного суб’єкта (аналога) до іншого (об’єкта). Вважається, що аналогія та абстракція є різними когнітивними процесами і часто аналогія передує абстракції. У вузькому сенсі аналогію розуміють як часткову подібність між двома речами, які не є подібними за іншими ознаками, або як міркування, у якому з подібності речей за одними ознаками роблять висновки щодо можливості подібності цих речей за іншими ознаками.

Встановлення аналогій є одним з інструментів розвитку науки. У теорії коливань аналогії у вигляді застосування процедур аналізу, розвинутих в одному розділі теорії коливань (наприклад, механічні коливання), до аналізу в інших розділах теорії коливань (наприклад, електромагнітних коливань) вже існують давно і навіть отримали назву “коливної взаємо-

Ци т у в ан н я: Рущицький Я.Я. Аналогії між класичною задачею про коливання двох зв’язаних тіл і некласичною задачею про поширення плоских хвиль у двофазній суміші. Допов. Наи. акад. наук Укр. 2021 № 2. C. 21-28. https://doi.org/10/15407/dopovidi2021.02.021 
допомоги” [1]. Це явище основане на ізоморфізмі закономірностей, коли коливання аналізуються не за ознакою фізичних явищ, а за формою закономірностей.

Дане повідомлення присвячене формам закономірностей і має метою встановлення ізоморфізму закономірностей при порівнянні аналізу однієї конкретної задачі теорії коливань і теж конкретної задачі про поширення хвиль.

Задача К (коливання) - класична лінійна задача про вертикальні гармонічні коливання двох зв’язаних між собою пружною пружиною абсолютно твердих тіл, підвішених на пружинах.

Задача X (хвилі) - некласична лінійна задача про поширення плоских поздовжніх хвиль у двофазній пружній суміші.

Аналіз аналогій між вказаними у назві повідомлення задачами проведено покроково.

\section{Крок 1.}

Постановки цих задач описані у відомих публікаціях [2-5], де вказані основні системи лінійних взаємозв’язаних диференціальних рівнянь.

Задача К. Основна система рівнянь така [2, 3]:

$$
\beta_{11} u_{1, t t}+\beta_{12} u_{2, t t}+\alpha_{11} u_{1}+\alpha_{12} u_{2}=0, \quad \beta_{12} u_{1, t t}+\beta_{22} u_{2, t t}+\alpha_{12} u_{1}+\alpha_{22} u_{2}=0,
$$

де $u_{\alpha}(t)(\alpha=1 ; 2)$ та $\alpha_{\alpha \alpha}-$ відповідно залежні від часу $t$ вертикальні зміщення тіл з масами $\beta_{\alpha \alpha}$ та параметри, що характеризують пружні властивості пружин, на яких підвішені тіла. Величини $\beta_{12}$ та $\alpha_{12}$ позначають так звану приєднану масу та параметр, що пов’язаний 3 пружними властивостями пружини, яка зв’язує два тіла.

Таким чином, зв'язаність системи (1) характеризується двома фізичними механізмами інерціальним та пружним, які в механічній моделі описуються параметрами $\beta_{12}$ та $\alpha_{12}$.

Задача Х. Основна система рівнянь така $[4,5]$ :

$$
\begin{aligned}
& \left(\rho_{11}-\rho_{12}\right) u_{1, t t}^{(1)}+\rho_{12} u_{1, t t}^{(2)}-\left(\lambda_{1}+2 \mu_{1}\right) u_{1,11}^{(1)}-\left(\lambda_{3}+2 \mu_{3}\right) u_{1,11}^{(2)}-\beta\left(u_{1}^{(1)}-u_{1}^{(2)}\right)=0, \\
& \rho_{12} u_{1, t t}^{(1)}+\left(\rho_{22}-\rho_{12}\right) u_{1, t t}^{(2)}-\left(\lambda_{2}+2 \mu_{2}\right) u_{1,11}^{(2)}-\left(\lambda_{3}+2 \mu_{3}\right) u_{1,11}^{(1)}+\beta\left(u_{1}^{(1)}-u_{1}^{(2)}\right)=0,
\end{aligned}
$$

де $u_{\alpha}\left(x_{1}, t\right)(\alpha=1 ; 2)$ - залежні від поздовжної координати $x_{1}$ та часу $t$ поздовжні зміщення двох фаз суміші $\lambda_{k}, \mu_{k}(k=1 ; 2 ; 3)-$ пружні постійні суміші, для якої конститутивні рівняння (лінійні рівняння зв'язку між напруженнями $\sigma_{i k}^{(\alpha)}$ та деформаціями $\left.\varepsilon_{i k}^{(\alpha)}=(1 / 2)\left(u_{i, k}^{(\alpha)}+u_{k, i}^{(\alpha)}\right)\right)$ мають вигляд

$$
\sigma_{i k}^{(\alpha)}=\lambda_{\alpha} \varepsilon_{m m}^{(\alpha)} \delta_{i k}+2 \mu_{\alpha} \varepsilon_{i k}^{(\alpha)}+\lambda_{3} \varepsilon_{m m}^{(\delta)} \delta_{i k}+2 \mu_{3} \varepsilon_{i k}^{(\delta)}
$$

Постійні густини $\rho_{\alpha \alpha}$ називають парціальними густинами суміші, тоді як $\rho_{12} \in$ постійною густиною, яка описує ефект приєднаної маси і має назву коефіцієнта інерційної взаємодії. Постійна $\beta$ має назву коефіцієнта зсувної взаємодії. Таким чином, зв’язаність системи (2) характеризується в механічній моделі суміші трьома фізичними механізмами інерціальним, який описується параметром $\rho_{12}$, зсувним (пружним), який описуються параметром $\beta$ та параметром $\lambda_{3}+2 \mu_{3}$, який описує взаємний вплив деформацій однієї фази суміші на напруження в іншій фазі суміші. 
Висновок. Система диференціальних рівнянь з частинними похідними (2) з двома невідомими функціями, залежними від двох змінних, може трактуватися як певне математичне узагальнення системи звичайних диференціальних рівнянь (1) з двома невідомими функціями, залежними від однієї змінної. Аналогія в математичній структурі систем цілком очевидна.

\section{Крок 2.}

Задача К. Після формулювання задачі і запису системи рівнянь (1) вводяться поняття потенціальної та кінетичної енергій системи маятників. Ці енергії мають простий вигляд квадратичних форм

$$
\mathcal{K}=\beta_{11} u_{1, t}^{2}+2 \beta_{12} u_{1, t} u_{2, t}+\beta_{22} u_{2, t}^{2}, \quad \mathcal{U}=\alpha_{11} u_{1}^{2}+2 \alpha_{12} u_{1} u_{2}+\alpha_{22} u_{2}^{2} .
$$

Далі аналізуються обмеження на шести фізичних постійних, які входять у систему рівнянь (1). Такі обмеження формулюють на основі додатності обох енергій і тоді їх записують таким чином:

$$
\beta_{11}>0, \beta_{22}>0, \beta_{11} \beta_{22}-\left(\beta_{12}\right)^{2}>0, \quad \alpha_{11}>0, \alpha_{22}>0, \alpha_{11} \alpha_{22}-\left(\alpha_{12}\right)^{2}>0 .
$$

Зазвичай, обмеження (5) стосуються постійних, які характеризують взаємодію між маятниками, і свідчать, що постійні не можуть бути довільними в рамках прийнятої моделі.

Задача Х. Вирази для енергій відомі і мають такий вигляд

$$
\begin{aligned}
& \mathcal{K}=(1 / 2)\left[\left(\rho_{11}-\rho_{12}\right)\left(u_{1, t}^{(1)}\right)^{2}+2 \rho_{12} u_{1, t}^{(1)} u_{1, t}^{(2)}+\left(\rho_{22}+\rho_{12}\right)\left(u_{1, t}^{(2)}\right)^{2}\right], \\
& \mathcal{U}=\left(\lambda_{1}+2 \mu_{1}\right)\left(u_{1,1}^{(1)}\right)^{2}+2\left(\lambda_{3}+2 \mu_{3}\right) u_{1,1}^{(1)} u_{1,1}^{(2)}+\left(\lambda_{2}+2 \mu_{2}\right)\left(u_{1,1}^{(2)}\right)^{2}-\beta\left(u_{1}^{(1)}-u_{1}^{(2)}\right)^{2}=0,
\end{aligned}
$$

Як випливає з формул (6) та (7), аналогія з кінетичною енергією повна, однак тут потенціальна енергія має складніший вигляд (включає два параметри взаємодії на відміну від задачі К, де всього один параметр) і тому додатна означеність квадратичної форми вже потребує більших обмежень. Отже, аналогія працює, але обмежень маємо дещо більше

$$
\begin{aligned}
& \rho_{11} \rho_{222}-\rho_{12}\left(\rho_{11}+\rho_{22}\right)>0, \\
& \lambda_{1}+2 \mu_{1}>0, \lambda_{2}+2 \mu_{2}>0,\left(\lambda_{1}+2 \mu_{1}\right)\left(\lambda_{2}+2 \mu_{2}\right)-\left(\lambda_{3}+2 \mu_{3}\right)^{2}>0, \beta>0 .
\end{aligned}
$$

Таким чином, аналогія щодо обмежень на параметри взаємодії дозволяє встановити такі обмеження в задачі X.

\section{Крок 3.}

Задача К. Розв'язок системи (1) шукаємо у вигляді $u_{\alpha}(t)=A_{\alpha} e^{i \omega t}$, тобто у вигляді гармонічного коливання з фазою $\omega t$. Підстановка цього розв’язку у систему (1) дає систему двох лінійних однорідних алгебраїчних рівнянь щодо невідомих постійних амплітуд $A_{\alpha}$

$$
\left(\alpha_{11}-\beta_{11} \omega^{2}\right) A_{1}+\left(\alpha_{12}-\beta_{12} \omega^{2}\right) A_{2}=0, \quad\left(\alpha_{12}-\beta_{12} \omega^{2}\right) A_{1}+\left(\alpha_{11}-\beta_{11} \omega^{2}\right) A_{2}=0 .
$$


Далі процедура класична. Спочатку прирівнюємо детермінант системи (4) до нуля і отримуємо біквадратне рівняння для знаходження власних частот (частотне рівняння) в задачі К

$$
\left(\beta_{11} \beta_{22}-\left(\beta_{12}\right)^{2}\right) \omega^{4}-\left(\alpha_{11} \beta_{22}+\alpha_{22} \beta_{11}-\left(\alpha_{12} \beta_{12}\right)^{2}\right) \omega^{2}+\left(\alpha_{11} \alpha_{22}-\left(\alpha_{12}\right)^{2}\right)
$$

Задача X. Тут крок 2 робимо аналогічно до описаного вище для задачі К. Перш за все, тому, що хвиля може розглядатися як коливання, яке поширюється в просторі. Розв'язок системи (2) шукаємо у вигляді $u_{1}^{(\alpha)}(t)=A_{o}^{(\alpha)} e^{i(k x-\omega t)}$, тобто у вигляді гармонічної хвилі з фазою $k x_{1}-\omega t$. Але фази в задачах $\mathrm{K}$ та $\mathrm{X}$ істотно різні. Тому тут доречно вже говорити про корисність використання аналогії. Підстановка розв'язку $u_{1}^{(\alpha)}(t)=A_{o}^{(\alpha)} e^{i(k x-\omega t)}$ у систему (2) дає систему двох лінійних однорідних алгебраїчних рівнянь щодо невідомих постійних амплітуд $A_{\alpha}$, яке для всіх типів хвиль називається дисперсійним рівнянням:

$$
\begin{aligned}
& \Delta_{\lambda+2 \mu} k^{4}-2 m_{2} k^{2} \omega^{2}+\Delta_{\rho} \omega^{4}=0, \\
& \Delta_{\lambda+2 \mu}=\left(\lambda_{1}+2 \mu_{1}\right)\left(\lambda_{2}+2 \mu_{2}\right)-\left(\lambda_{3}+2 \mu_{3}\right)^{2} ; \\
& 2 m_{2}=\left(\lambda_{1}+2 \mu_{1}\right) \rho_{11}+\left(\lambda_{2}+2 \mu_{2}\right) \rho_{22}-\left(\left(\lambda_{1}+2 \mu_{1}\right)+\left(\lambda_{2}+2 \mu_{2}\right)+2\left(\lambda_{3}+2 \mu_{3}\right)\right)\left(\frac{\beta}{\omega^{2}}+\rho_{12}\right), \\
& \Delta_{\rho}=\rho_{11} \rho_{22}-\left(\rho_{11}+\rho_{22}\right)\left(\frac{\beta}{\omega^{2}}+\rho_{12}\right) .
\end{aligned}
$$

Висновок. Частотне рівняння (10) є алгебраїчним біквадратним, як і дисперсійне рівняння (11). Тому детальний аналіз частотного рівняння в класичній задачі К може служити аналогом (схемою) для такого ж аналізу дисперсійного рівняння в некласичній задачі X, яка не так детально досліджена.

\section{Крок 4.}

Задача К. Розв'язок частотного рівняння включає чотири значення власної частоти ко ливної системи $\left( \pm \omega_{1}, \pm \omega_{2}\right)$ і тому загальний розв'язок системи (1) у вигляді гармонічних коливань записується як сума чотирьох коливань з довільними амплітудами, які можна визначити з чотирьох початкових умов (значень парціальних зміщень $u_{\alpha}$ i їх швидкостей у початковий момент часу)

$$
\begin{aligned}
& u_{1}(t)=A_{1} e^{i \omega_{1} t}+\bar{A}_{1} e^{-i \omega_{1} t}+l_{2}\left(A_{2} e^{i \omega_{2} t}+\bar{A}_{2} e^{-i \omega_{2} t}\right), \\
& u_{2}(t)=l_{1}\left(A_{1} e^{i \omega_{1} t}+\bar{A}_{1} e^{-i \omega_{1} t}\right)+A_{2} e^{i \omega_{2} t}+\bar{A}_{2} e^{-i \omega_{2} t} .
\end{aligned}
$$

У формулі (12) введені так звані коефіцієнти розподілу амплітуд $l_{\alpha}$ за такою процедурою: розв'язок для першої (другої) власної частоти $u_{1}(t)=A_{1} e^{i \omega_{1} t}, u_{2}(t)=l_{1} A_{1} e^{i \omega_{1} t}$ підставляється у перше (друге) рівняння системи (1), яке при цьому повинно задовольнятися тотожно, і тому

$$
l_{1}=-\left[\left(\alpha_{11}-\beta_{11} \omega_{1}^{2}\right) /\left(\alpha_{12}-\beta_{12} \omega_{1}^{2}\right)\right]=-\left[\left(\alpha_{12}-\beta_{12} \omega_{1}^{2}\right) /\left(\alpha_{22}-\beta_{22} \omega_{1}^{2}\right)\right],
$$




$$
l_{2}=-\left[\left(\alpha_{22}-\beta_{22} \omega_{2}^{2}\right) /\left(\alpha_{12}-\beta_{12} \omega_{2}^{2}\right)\right]=-\left[\left(\alpha_{12}-\beta_{12} \omega_{2}^{2}\right) /\left(\alpha_{11}-\beta_{11} \omega_{2}^{2}\right)\right] .
$$

3 урахуванням позначень (13) та (14) розв’язок (12) можна записати стисліше через матрицю розподілу амплітуд

$$
\left(\begin{array}{l}
u_{1}(t) \\
u_{2}(t)
\end{array}\right)=\left(\begin{array}{cc}
1 & l_{2} \\
l_{1} & 1
\end{array}\right)\left(\begin{array}{c}
A_{1} e^{i \omega_{1} t}+\bar{A}_{1} e^{-i \omega_{1} t} \\
A_{2} e^{-i \omega_{2} t}+\bar{A}_{2} e^{-i \omega_{2} t}
\end{array}\right) .
$$

Задача Х. Розв’язок дисперсійного рівняння включає чотири власні значення довжини хвилі хвильової системи $\left( \pm k_{1}, \pm k_{2}\right)$. Одразу слід зазначити, що від’ємні значення хвильових чисел у теорії хвиль не мають фізичного сенсу, як і такі ж значення частот у теорії коливань. Розв’язок дисперсійного рівняння (6) записуємо у вигляді

$$
k_{1,2}^{2}=\frac{\omega^{2}}{\Delta_{\lambda+2 \mu}}\left\{m_{2} \pm \sqrt{m_{2}^{2}-\Delta_{\lambda+2 \mu} \Delta_{\rho}}\right\},
$$

або

$$
\begin{aligned}
& k_{1,2}^{2}=\frac{\omega^{2}}{2\left[\left(\lambda_{1}+2 \mu_{1}\right)\left(\lambda_{2}+2 \mu_{2}\right)-\left(\lambda_{3}+2 \mu_{3}\right)\right]^{2}} \times \\
& \left\{\begin{array}{l}
\left(\lambda_{1}+2 \mu_{1}\right) \rho_{11}+\left(\lambda_{2}+2 \mu_{2}\right) \rho_{22}-\left(\left(\lambda_{1}+2 \mu_{1}\right)+\left(\lambda_{2}+2 \mu_{2}\right)+2\left(\lambda_{3}+2 \mu_{3}\right)\right)\left(\frac{\beta}{\omega^{2}}+\rho_{12}\right) \pm \\
\pm \sqrt{\left[\left(\lambda_{1}+2 \mu_{1}\right) \rho_{11}+\left(\lambda_{2}+2 \mu_{2}\right) \rho_{22}-\left(\left(\lambda_{1}+2 \mu_{1}\right)+\left(\lambda_{2}+2 \mu_{2}\right)+2\left(\lambda_{3}+2 \mu_{3}\right)\right)\left(\frac{\beta}{\omega^{2}}+\rho_{12}\right)\right]^{2}}-
\end{array},\right.
\end{aligned}
$$

або у записі через фазові швидкості $v_{\alpha}=\left(\omega / k_{\alpha}\right)$

$$
v_{1,2}^{2}=\frac{1}{\Delta_{\rho}}\left\{m_{2} \pm \sqrt{m_{2}^{2}-\Delta_{\lambda+2 \mu} \Delta_{\rho}}\right\} .
$$

Таким чином, загальний розв’язок системи (2) у вигляді гармонічних хвиль можна представити як суперпозицію двох гармонічних хвиль (двох мод), які відрізняються хвильовими числами $k_{\alpha}$ чи фазовими швидкостями $v_{\alpha}=\left(\omega / k_{\alpha}\right)$

$$
u_{1}^{(\alpha)}\left(x_{1}, t\right)=A_{o}^{(\alpha)} e^{-i\left(k_{\alpha} x-\omega t\right)}+l_{\delta}\left(k_{\delta}\right) A_{o}^{(\delta)} e^{-i\left(k_{\delta} x-\omega t\right)} .
$$

У формулі (13) по аналогії з задачею К введені коефіцієнти розподілу амплітуд $l_{\alpha}\left(k_{\alpha}\right)$ за такою ж процедурою: розв'язок для першої (чи другої) моди $u_{1}(t)=A_{o}^{1} e^{i\left(k_{1} x-\omega t\right)}, u_{2}(t)=$ $=l_{1}\left(k_{1}\right) A_{o}^{1} e^{i\left(k_{1} x-\omega t\right)}$ підставляємо у перше (чи друге) рівняння системи $(2)$, яке при цьому повинно задовольнятися тотожно, і тому 


$$
\begin{aligned}
& l_{1}\left(k_{1}\right)=-\frac{\left(\lambda_{1}+2 \mu_{1}\right) k_{1}^{2}-\left(\left(\rho_{11}-\rho_{12}\right) \omega^{2}+\beta\right)}{\left(\lambda_{3}+2 \mu_{3}\right) k_{1}^{2}+\beta-\rho_{12} \omega^{2}} A_{11}=-\frac{\left(\lambda_{3}+2 \mu_{3}\right) k_{1}^{2}+\beta-\rho_{12} \omega^{2}}{\left(\lambda_{2}+2 \mu_{2}\right) k_{1}^{2}-\left(\left(\rho_{22}-\rho_{12}\right) \omega^{2}+\beta\right)} A_{11}, \\
& l_{1}\left(k_{1}\right)=-\frac{\left(\lambda_{1}+2 \mu_{1}\right) k_{1}^{2}-\left(\left(\rho_{11}-\rho_{12}\right) \omega^{2}+\beta\right)}{\left(\lambda_{3}+2 \mu_{3}\right) k_{1}^{2}+\beta-\rho_{12} \omega^{2}} A_{11}=-\frac{\left(\lambda_{3}+2 \mu_{3}\right) k_{1}^{2}+\beta-\rho_{12} \omega^{2}}{\left(\lambda_{2}+2 \mu_{2}\right) k_{1}^{2}-\left(\left(\rho_{22}-\rho_{12}\right) \omega^{2}+\beta\right)} A_{11} .
\end{aligned}
$$

3 врахуванням позначень (20) та (21) розв'язок (18) можна записати стисліше через матрицю розподілу амплітуд:

$$
\left(\begin{array}{l}
u_{1}^{(1)}\left(x_{1}, t\right) \\
u_{1}^{(2)}\left(x_{1}, t\right)
\end{array}\right)=\left(\begin{array}{cc}
1 & l_{2}\left(k_{2}\right) \\
l_{1}\left(k_{1}\right) & 1
\end{array}\right)\left(\begin{array}{l}
A_{o}^{(1)} e^{-i\left(k_{1} x-\omega t\right)} \\
A_{o}^{(2)} e^{-i\left(k_{2} x-\omega t\right)}
\end{array}\right) .
$$

Висновок. Формальна аналогія між представленнями розв'язків (15) та (22) існує, однак у них вже закладені відмінності, що спричиняють лише часткову можливість перенесення елементів повного аналізу задачі К у неповний на цей час аналіз задачі Х. Тому доцільно далі розглянути кожен елемент окремо.

\section{Крок 6.}

Задача К. Одним із головних елементів аналізу є введення парціальних частот і дослідження частотного рівняння на предмет взаємозв'язку між власними і парціальними частотами. Парціальними частотами тут називають власні частоти $n_{\alpha}=\sqrt{\left(\alpha_{\alpha \alpha} / \beta_{\alpha \alpha}\right)}$, які мають окремо взяті невзаємодіючі маятники. Вказаний взаємозв'язок аналізується за допомогою трактування частотного рівняння (10) як опуклої вниз параболи $\Phi(\omega)$, яка перетинає вісь $O \omega$ в точках, що відповідають власним частотам. Для цього на основі частотного рівняння вибирається функція

$$
\Phi(\omega)=\left(\beta_{11} \beta_{22}-\left(\beta_{12}\right)^{2}\right) \omega^{4}-\left(\alpha_{11} \beta_{22}+\alpha_{22} \beta_{11}-\left(\alpha_{12} \beta_{12}\right)^{2}\right) \omega^{2}+\left(\alpha_{11} \alpha_{22}-\left(\alpha_{12}\right)^{2}\right),
$$

з аналізу якої маємо

$$
\Phi(0)>0, \Phi\left(n_{\alpha}\right)=-\left[\beta_{12}\left(\alpha_{\alpha \alpha} / \beta_{\alpha \alpha}\right)-\alpha_{12}\right]^{2}<0
$$

і далі необхідний факт, що парціальні частоти лежать між власними

$$
\omega_{1}<n_{1}<n_{2}<\omega_{2} .
$$

Це трактується так, що внесення взаємодії між маятниками призводить до більшої відмінності між власними частотами (і чим більша взаємодія, тим більша відмінність).

Задача X. Тут аналогом парціальних частот є парціальні хвильові числа

$$
k_{P \alpha}=\omega \sqrt{\rho_{\alpha \alpha} /\left(\lambda_{\alpha}+2 \mu_{\alpha}\right)} .
$$

Побудований за (26) графік є прямою лінією, яка проходить під певним кутом до осі абсцис (осі частот) через початок координат і свідчить про недисперсивність відповідних хвиль. Але дисперсійне рівняння (11) дає розв'язки, які відповідають дисперсивним хвильовим модам. Крім того, друга мода не існує в діапазоні частот $\left(0 ; \omega_{c u t}=\right.$ $\left.=\sqrt{\beta\left(\rho_{11}+\rho_{22}\right) /\left[\rho_{11} \rho_{22}-\rho_{12}\left(\rho_{11}+\rho_{22}\right)\right]}\right)$. Частоту $\omega_{c u t}$, при якій біжуча хвиля переходить $\mathrm{y}$ 
експоненціально затухаючу, називають частотою запирання або частотою відсікання. Ця частота залежить від парціальних густин суміші та коефіцієнта інерціальної взаємодії. Отже, аналогія не є прямою.

Розглянемо функцію, пов’язану з дисперсійним рівнянням

$$
\Psi(k)=\Delta_{\lambda+2 \mu} k^{4}-2 m_{2} k^{2} \omega^{2}+\Delta_{\rho} \omega^{4} .
$$

Графіком цієї функції є парабола, яка перетинає вісь $O k$ в точках, що відповідають хвильовим числам описаних вище двох мод. Оскільки $\Psi(0)=\Delta_{\rho}$, то парабола змінює напрямок опуклості при переході значення частоти через значення частоти запирання, зовсім не подібно до того як це є в задачі К. Порахуємо далі значення функції в точках, що відповідають парціальним хвильовим числам (задля компактності запису введемо позначення $\left.a_{i}=\lambda_{i}+2 \mu_{i}\right)$

$$
\Psi\left(k_{P \alpha}\right)=-\omega^{4}\left\{\begin{array}{l}
\left(a_{3} / a_{\alpha}\right)^{2}\left(\rho_{\alpha \alpha}\right)^{2}+\left[\left(a_{1}+a_{2}+2 a_{3}\right) / a_{\alpha}\right]\left[\left(\beta / \omega^{2}\right)+\rho_{12}\right] \rho_{\alpha \alpha}+ \\
+\left(\rho_{11}+\rho_{22}\right)\left[\left(\beta / \omega^{2}\right)+\rho_{12}\right]
\end{array}\right\}<0 .
$$

Таким чином, і у цьому випадку аналогія діє. Однак задача X має деякі новели, як-от залежність мод від частоти чи запирання однієї з мод, чи одночасне існування обох хвильових мод у кожному компоненті суміші. Тому подальший аналіз ускладнюється.

Загальний висновок. Теорія двофазних сумішей у своєму розвитку в області теорії хвиль може успішно використовувати аналогії з відповідних задач теорії коливань двох взаємозв'язаних коливних систем. 3 показаних аналогій випливає більш загальний факт, що виявлений майже 100 років тому академіком Мандельштамом, механізм взаємодопомоги в теорії коливань за цей час розширив свій вплив і на теорію хвиль. Якщо коментувати спостережені аналогії більш загально, то теорія хвиль у своєму розвитку може успішно використовувати аналогії з відповідних розділів теорії коливань.

\section{ЦИТОВАНА ЛІТЕРАТУРА}

1. Академик Л.И. Мандельштам. К 100-летию со дня рождения. Москва: Наука, 1979. 312 с.

2. Стрелков С.П. Введение в теорию колебаний. 2-е изд. Москва: Наука, 1964. 440 с.

3. Schmitz T.L., Smith K.S. Mechanical Vibrations. Modeling and Measurement. $2^{\text {nd }}$ ed. New York: Springer, 2021. 426 p.

4. Рущицкий Я.Я. Элементы теории смеси. Киев: Наук. думка, 1991. 160 с.

5. Рущицький Я.Я., Цурпал С.І. Хвилі в матеріалах з мікроструктурою. Київ: Інститут механіки ім. С.П.Тимошенка, 1998. 377 с.

6. Rushchitsky J.J. Theory of waves in materials. Copenhagen: Ventus Publishing ApS, 2011. 270 p.

Надійшло до редакції 10.02.2021

\section{REFERENCES}

1. Academician L.I.Mandelstam. (1979). To Centenary of Birthday K. Moscow: Nauka (in Russian).

2. Strelkov, S.P. (1964). Introduction in Theory of Vibrations. $2^{\text {nd }}$ ed. Moscow: Nauka (in Russian).

3. Schmitz, T.L. \& Smith, K.S. (2021).Mechanical Vibrations. Modeling and Measurement. $2^{\text {nd }}$ ed. New York: Springer. 
4. Rushchitsky, J.J. (1991). Elements of the theory of mixtures. Kiev: Naukova Dumka (in Russian).

5. Rushchitsky, J.J. \& Tsurpal, S.I. (1998). Waves in Materials with Microstructure. Kyiv, S.P.Timoshenko Institute of Mechanics (in Ukrainian).

6. Rushchitsky, J.J. (2011).Theory of waves in materials. Copenhagen: Ventus Publishing

Received 10.02.2021

\section{J.J. Rushchitsky}

S.P. Timoshenko Institute of Mechanics of the NAS of Ukraine, Kyiv

E-mail: rushch@inmech.kiev.ua

\section{ANALOGIES BETWEEN THE CLASSICAL PROBLEM ON VIBRATIONS \\ OF TWO COUPLED BODIES AND THE NONCLASSICAL PROBLEM ON PROPAGATION OF PLANE WAVES IN THEORY OF TWO-PHASE MIXTURES}

In order to identify analogies in the procedures of analysis, two problems are described and commented on: the classical problem (problem V) on harmonic vibrations of two interconnected rigid bodies suspended on the springs, and the nonclassical problem (problem W) on the propagation of plane longitudinal waves in the twophase elastic mixture. A number of analogies are constructed between these problems, which are described in the form of 6 steps of the comparative analysis of problems $V$ and $W$, each of which corresponds to a specific analogy. Emphasis is placed on the usefulness of the observed analogies for the analysis of the problem of waves. Thus, it is shown that the theory of two-phase mixtures in its development in the field of wave theory can successfully use the analogies from the corresponding problems of the theory of vibrations of two coupled oscillating systems. The more general fact follows from the analogies shown that the mechanism of mutual aid in the theory of vibrations discovered almost 100 years ago by Academician Mandelstam extended its influence to the theory of waves during this time.

Keywords: oscillations of two coupled bodies, propagation of elastic plane wave in two-phase mixture, analogies in procedures of analysis. 